\title{
Patient aspects: A review of fifty-eight Danish HTA reports
}

\author{
Helle Ploug Hansen, Anne Lee, Christian Balslev van Randwijk \\ University of Southern Denmark
}

Objectives: The objective of this study is to describe how patient aspects are assessed in Danish HTA reports, thereby contributing to the ongoing international debates concerning patient aspects in HTAs.

Methods: Fifty-eight Danish HTA reports published from 1999 to 2010 were read systematically, focusing on the inclusion of patient aspects, the methods used to generate data, and if and how clinical recommendations concerning patient aspects were drawn.

Results: Most of the fifty-eight HTA reports had a separate chapter about patient aspects. All reports included literature reviews for patient aspects. There was, however, much variation in the ways in which the authors presented and discussed their review methods. The most frequently used databases for the literature search were medical and HTA databases. More than half of the reports included primary research, either quantitative or qualitative methods, a few used both kinds of methods. Whereas some mentioned the importance of including patient aspects in daily clinical practice, others provided ideas on how to improve patient information or recommended changes in healthcare practices. Conclusions: Danish HTA reports do, to a large extent, include patient aspects in the assessment and in the final conclusions of the reports. If health policy and decision making is to be patient-focused, it is important that HTAs in the future integrate patient aspects in recommendations of HTA. Further improvement in assessments of patient aspects, in relation to use and description of methodologies and theoretical considerations, will assist producing the relevant evidence for these recommendations.

Keywords: Patient aspects, Methods, Recommendations, Primary research, Secondary research

There is an increasing focus on designing health services as "patient focused," including involvement of patients in their own care, as well as patients and citizens in decisions about healthcare services and delivery. This general and increasing attention is reflected in a growing focus on patient aspects and patient involvement in health technology assessment (HTA), and how this focus might be strengthened (1).

A review on the inclusion of patient and/or organizational aspects in HTA reports published by INATHA members 2000-05 showed a great variation; in relation to explicit inclusion of the aspects to be assessed as well as in how the aspects were addressed. This has the effect of leaving the reader uncertain as to whether or not the relevant issues were included, and if they were assessed using a relevant method- ology $(4 ; 5)$. Based on the results from this review, an interest emerged for reviewing the Danish HTAs in relation to how these reports have addressed patient aspects.

In Denmark, there is a long tradition for conducting HTAs within a framework of four key elements: (i) technology, (ii) patient, (iii) organization, and (iv) economy. In the recently updated Danish Handbook of HTA (3), it is stated that the patient element must focus on patient aspects, such as patient perspectives, needs, experiences, preferences, and/or acceptance of a given technology. In Table 1, an overview of recommendations for patient assessments in the Danish Handbook is presented.

The objective of this study is to describe the management, presentation, and significance of the assessment of 
Table 1. Danish Recommendations for Assessment of Patient Aspects (3)

\section{Patient aspects:(Highlights} from chapter 7)

Knowledge production (Highlights from chapter 7)

Generating secondary data: (Highlights from chapter 3)

Generating primary data: (Highlights from chapter 5)
- Need to be explored when the respective technology, organization and/or economic aspects concern (affect and influence) people, i.e., in most cases

- Includes: knowledge, experiences, preferences, needs, expectations, visions, requirements, economy, organization, influence of customs, attitudes, and traditions and influence regarding everyday life, self-care, and empowerment.

Any research results implicitly or explicitly entail a specific understanding of knowledge, i.e., whether knowledge is something we have or whether it is something we produce and reproduce in different social relations and in different contexts.

HTA is to a great extent based on existing knowledge from published and unpublished studies. Incorporation of literature-based documentation is conditioned by the literature being searched and assessed by internationally recognized methods.

Initiation of primary investigations is only considered relevant if the knowledge that can be gained from a prior review of the literature proves inadequate. The main qualitative methods for generating data are: individual interviews, focus group discussions and interviews, participant observation, and fieldwork. The main quantitative methods for generating data are questionnaires and surveys. patient aspects in Danish HTA reports and thereby contribute to the ongoing national and international debates about patient aspects in HTAs.

\section{METHODS}

A review of the sixty-two Danish HTA reports published between January 1999 and February 2010 either as National HTA reports or as reports funded by a DACHETA grant was conducted (9) (Supplementary Table 1, which is available at www.journals.cambridge.org/thc2011024). The inclusion criteria being assessment of patient aspects meant that four reports were excluded: Two focused exclusively on economic evaluation $(8 ; 10)$ and two reports had no specific focus on patient aspects $(6 ; 7)$. Four questions guided our reading of the fifty-eight reports included in the review: (i) How are patient aspects addressed in the reports? (ii) What kind of data is included and how are they generated? (iii) Are the results about patient aspects integrated in the concluding parts of the report? (iv) Are there any changes in how patient aspects have been investigated and presented in HTA-reports over the years?

\section{RESULTS}

\section{How Are Patient Aspects Addressed in the Reports?}

Objectives and/or research questions were specifically stated concerning the patient aspects in fifty-four of the fifty-eight reports. Four reports did not include a specific objective and were published before 2006. In fifty-one of the fifty-eight HTA reports there was a separate chapter about patient aspects. Of the remaining seven reports, two stood out. Here, the authors argued that because of their theoretical approach, patients aspects must be incorporated in other elements of the report. In one of these, theories of knowledge and knowledge production were used to illustrate the ward round at a hospital as a production of knowledge, aimed at managing the diagnostic and therapeutic work (number 25 in table 2). Here, patient aspects were integrated with the organizational element. In the other report, actor-network theories (ANT) were used to understand certain aspects of poly-pharmacologic treatment of type 2 diabetes (number 37 in Table 2). Here, patient aspects were integrated in the elements of technology and organization. The remaining five reports did not specify reasons for not having a separate chapter for patient aspects.

\section{What Kind of Data Is Included and How Are They Generated?}

The fifty-eight reports are presented in Table 2. All of the fifty-eight reports included literature in a systematic or unsystematic way and 34 (59 percent) of the reports included primary data to answer the HTA questions (Table 2).

\section{Secondary Research}

While all the reports included some kind of literature search, there was a considerable variation in relation to if and how the authors presented and discussed their choice of search, regarding the purpose and perspectives of the study. In twelve reports (21 percent), a systematic literature search was included specifically for the patient aspects. In one report, a systematic literature search was included but the databases used were not presented. In twenty-nine reports (50 percent), a collective systematic literature search was included 
Table 2. The Fifty-eight Danish Reports

\begin{tabular}{|c|c|c|c|}
\hline Report topic & Key information & Research Methods & Included in \\
\hline 1. Back pain 1999 & Topic-specific issues & Secondary & Recommendations \\
\hline 2. Beta-interferon treatment 1999 & Topic-specific issues & Secondary & Research needed \\
\hline 3. IVF treatment 2001 & Topic-specific issues & Primary & Summary \\
\hline 4. Photo thermal treatment 2002 & Quality of life & Secondary & Recommendations \\
\hline 5. Screening for Chlamydia 2002 & Topic-specific issues & Primary & Recommendations \\
\hline 6. Chronic hepatitis C 2002 & Topic-specific issues & Primary + secondary & Summary \\
\hline 7. Rheumatoid arthritis 2002 & Topic-specific issues & Secondary & Summary \\
\hline 8. Implantation, genetic diagnosis 2002 & Ethics & Primary + secondary & Recommendations \\
\hline 9. Telemedicine, acute heart 2002 & Topic-specific issues & Secondary & Research needed \\
\hline 10. Hepatitis B vaccination 2003 & Topic-specific issues & Primary + secondary & Recommendations \\
\hline 11. Type 2 - diabetes 2003 & Topic-specific issues & Secondary & Summary \\
\hline 12. Refractive surgery 2004 & Patient satisfaction & Primary + secondary & Recommendations \\
\hline 13. Screening for breast cancer 2004 & Patient satisfaction & Primary + secondary & Recommendations \\
\hline 14. Hospice 2005 & Patient satisfaction & Primary & Recommendations \\
\hline 15. Caesarean section 2005 & Ethics & Secondary & Recommendations \\
\hline 16. Nutritional care 2005 & Patient satisfaction & Primary + secondary & Recommendations \\
\hline 17. Fast track colonic surgery 2005 & Patient satisfaction & Primary + secondary & Summary \\
\hline 18. Cervical cancer screening 2005 & Topic-specific issues & Secondary & Summary \\
\hline 19. Home treatment, stroke 2005 & Topic-specific issues & Primary + secondary & Recommendations \\
\hline 20. First trimester abortion 2005 & Wellbeing & Secondary & Recommendations \\
\hline 21. Colon investigation 2005 & Topic-specific issues & Secondary & Recommendations \\
\hline 22. Urinary Tract Symptoms 2005 & Briefly about patient & Secondary & Research needed \\
\hline 23. X-rays of lower back 2006 & Patient satisfaction & Secondary & Recommendations \\
\hline 24. Alcohol dependence 2006 & Topic-specific issues & Secondary & Recommendations \\
\hline 25. Ward Rounds 2006 & Organizational aspects & Primary + secondary & Recommendations \\
\hline 26. Apnea 2006 & Topic-specific issues & Primary + secondary & Recommendations \\
\hline 27. Dialysis in Renal Failure 2006 & Quality of life & Primary + secondary & Recommendations \\
\hline 28. Cardiac rehabilitation 2006 & Patient satisfaction & Secondary & Summary \\
\hline 29. Preventive health screenings 2006 & Topic-specific issues & Secondary & Summary \\
\hline 30. Pain school 2006 & Topic-specific issues & Primary & Recommendations \\
\hline 31. Affective disorders 2006 & Topic-specific issues & Primary + secondary & Recommendations \\
\hline 32. Ultrasound during pregnancy 2006 & Psychological side-effects & Primary & Recommendations \\
\hline 33. Problem wounds 2006 & Topic-specific issues & Primary + secondary & Summary \\
\hline 34. Cross-sectorial cooperation 2006 & Quality of life & Primary + secondary & Summary \\
\hline 35. Surgery for vaginal prolapsed 2006 & Quality of treatment & Primary & Recommendations \\
\hline 36. Knee surgery 2007 & Topic-specific issues & Secondary & Summary \\
\hline 37. Pharmacological Treatment 2007 & Topic-specific issues & Primary + secondary & Recommendations \\
\hline 38. Home visits elderly 2007 & Patient satisfaction & Primary + secondary & Summary \\
\hline 39. Surgery for obesity 2007 & Quality of life & Secondary & Research needed \\
\hline 40. HPV 2007 & Topic-specific issues & Primary+ secondary & Recommendations \\
\hline 41. Endoscopy, small intestine 2007 & Patient satisfaction & Primary & Recommendations \\
\hline 42. Colorectal cancer 2007 & Topic-specific issues & Primary + secondary & Recommendations \\
\hline 43. Multidisciplinary pain centre 2007 & Quality of life. & Primary & Recommendations \\
\hline 44. Depth of anesthesia 2007 & Topic-specific issues & Secondary & Summary \\
\hline 45. Screening for colorectal cancer 2008 & Patient participation & Secondary & Research needed \\
\hline 46. Caries in primary teeth 2008 & Topic-specific issues & Primary & Recommendations \\
\hline 47. Dementia 2008 & Topic-specific issues & Secondary & Summary \\
\hline 48. Pain treatment 2008 & Patient satisfaction & Primary + secondary & Summary \\
\hline 49. Patient involvement 2008 & Patient narratives & Primary & Recommendations \\
\hline 50. Electronic patient record 2008 & Patient satisfaction & Primary & Summary \\
\hline 51. Patient education 2009 & Education & Secondary & Summary \\
\hline 52. Smoking cessation 2009 & Patient satisfaction & Primary & Summary \\
\hline 53. Screening, hemoglobin 2009 & Attitudes & Secondary & Summary \\
\hline 54. Bladder catheterization 2009 & Topic-specific issues & Primary + secondary & Recommendations \\
\hline 55. Home visits, severe COPD 2009 & Coping & Primary + secondary & Summary \\
\hline 56. Gynecological cancer 2009 & Quality of life & Primary + secondary & Recommendations \\
\hline 57. Percutaneous vertebroplasty 2010 & Topic-specific issues & Secondary & Summary \\
\hline 58. Back pain 2010 & Quality of life & Secondary & Recommendations \\
\hline
\end{tabular}


for all the (four) aspects of the report. In sixteen reports (28 percent), the literature search followed a more experience based process, where the authors' browsed the literature. The most frequently used databases were medical, such as Medline, Pubmed, Embase, Cinahl, and HTA databases. A few reports included sociological or anthropological databases, such as Sociological Abstracts.

\section{Primary Research}

In thirty-four (59 percent) of the reports, primary data were generated. Sixteen of these reports (47 percent) used quantitative methods, thirteen (38 percent) used qualitative methods, and five reports (15 percent) used both kinds of methods. Of the twenty-four reports that did not produce primary data, twenty-two (92 percent) relied on literature reviews. The remaining two reports relied on data generated in other reports or studies, and engaged with literature related to those, without making systematic literature reviews.

\section{Are the Results About Patient Aspects Integrated in the Concluding Parts of the Report?}

All fifty-eight reports addressed patient aspects either in their conclusion, syntheses and/or recommendations. The inclusion of patient aspects might be categorized as; included in the recommendations of the report or included in the summary of the report. Thirty-four reports (59 percent) included patient aspects in the recommendations of the report. Twentysix of these included recommendations for future clinical practice based on patient aspects. One example on future clinical practice was a recommendation about how to organize a specific form of treatment. It was argued that this specific form of treatment must be kept within the primary healthcare sector to avoid unnecessary pathologization of the patient (number 1 in Table 2). Another example was a recommendation about a greater flexibility in the understanding of the patient as an active agent (number 49 in Table 2).

Eight reports recommended an improvement in patient information. One example was a recommendation to increase the information to social groups with different ethnic and cultural backgrounds (number 5 in Table 2). Another example was reflections on how information, regarding side effects in relation to a specific treatment, can be handled most effectively (number 40 in Table 2). None of the recommendations were based on, or referred to, theories of communication and information.

In the remaining twenty-four reports (41 percent), the patient aspects were included in the concluding part of the report. The text focused either on how patient aspects had been investigated (in nineteen reports) or stated that the knowledge we have today about patient aspects have limitations (in five reports). One example was a report in which it was concluded that there was no knowledge available about the patients' physical, psychological, and social challenges in relation to the specific disease and its treatment (number 39 in Table 2). No conclusions or recommendations concerning patient aspects were drawn in these reports.

Of the twenty-six reports including patient aspects in the recommendations for future clinical practice, twenty (77 percent) had generated new empirical data. This is a significantly higher proportion than that of all reports generating new empirical data (59 percent). Eleven of the twenty reports (55 percent) used qualitative methods for the assessment and the rest used quantitative methods.

\section{Are There Any Changes in How Patient Aspects Have Been Investigated and Presented in HTA Reports Over the Years?}

By combining the distribution of reports in the years 19992010 and the above results, we were able to identify some chronological trends in relation to how the literature search was conducted, and which methods were used for generating primary data. There was a tendency for an increase in the systematic literature search on patient aspects. Whereas this was the case for up to 17 percent of the reports published in the period 1999-2005, the proportion had risen from 17 to 33 percent for the reports published between 2006 and 2009.

Also, the proportion of reports generating primary data changed across the years investigated. Although 53 percent of the reports published in the years 1999-2005 included primary data, the percentage for 2006-09 had risen to 65 percent. The two reports published in 2010 were different in that they neither included a specific literature search on patient aspects nor generated primary data for the assessment.

When looking at methods more specifically in the reports, the use of quantitative methods was published in reports from 2001, and the use of qualitative methods in the reports from 2002. In 2002, reports using both quantitative and qualitative methods were published (Fig. 1). There was no difference in relation to patient aspects included in the recommendations or in the summary of the reports during 1999-2010 (Fig. 2).

\section{DISCUSSION}

The present review finds that patient aspects were included in fifty-eight of sixty-two Danish HTA reports published between 1999 and 2010, and that fifty-four of the fifty-eight reports included objectives and/or research questions for patient aspects. This shows that Danish HTA reports, to a greater extent than most, include these aspects $(4 ; 5)$ and does it in a considered manner.

Although all the Danish reports included some literature for the assessment of patient aspects, only a minority included a systematic literature search specific for the aspects. More than half of the reports generated empirical data, using qualitative as well as quantitative methods. Assessing a period over 10 years showed an increase in the specific literature search on patient aspects and in inclusion of primary 
Hansen et al.

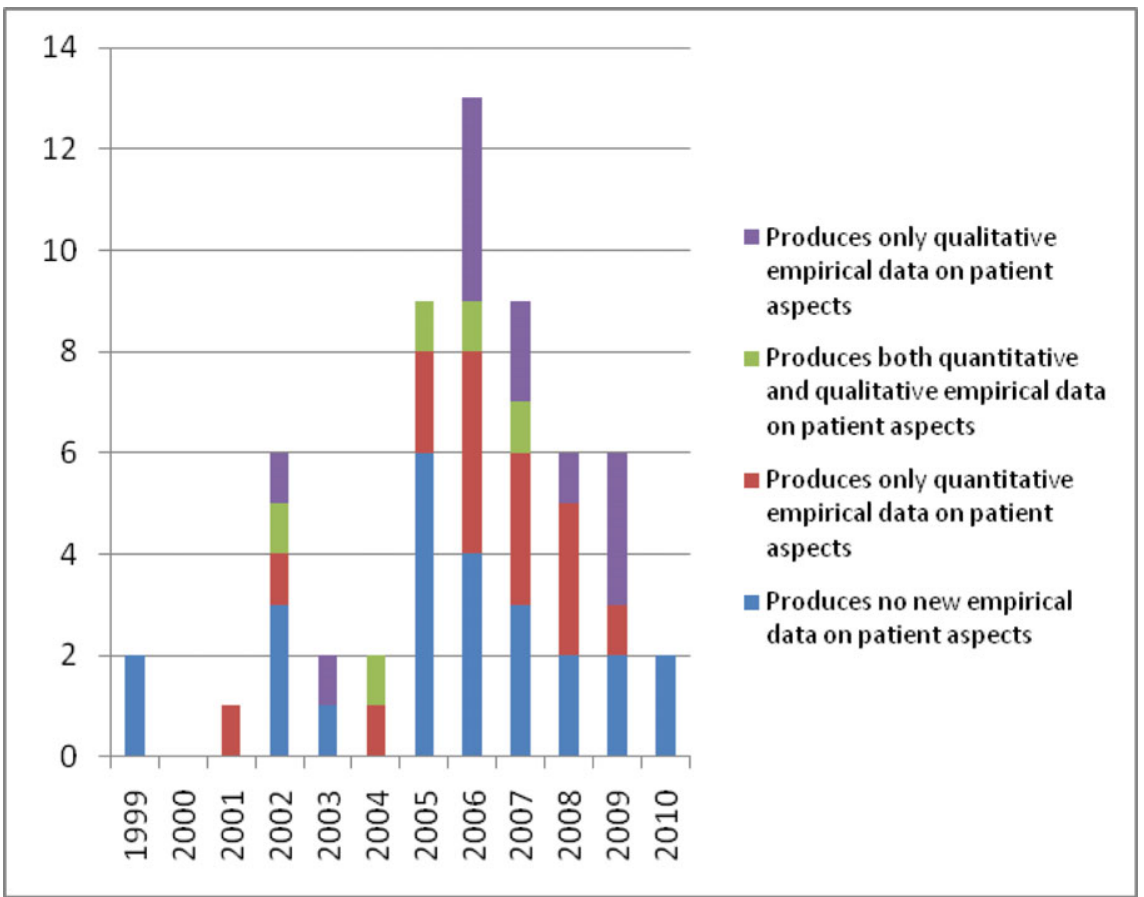

Figure 1. Inclusion of empirical data and methods used.

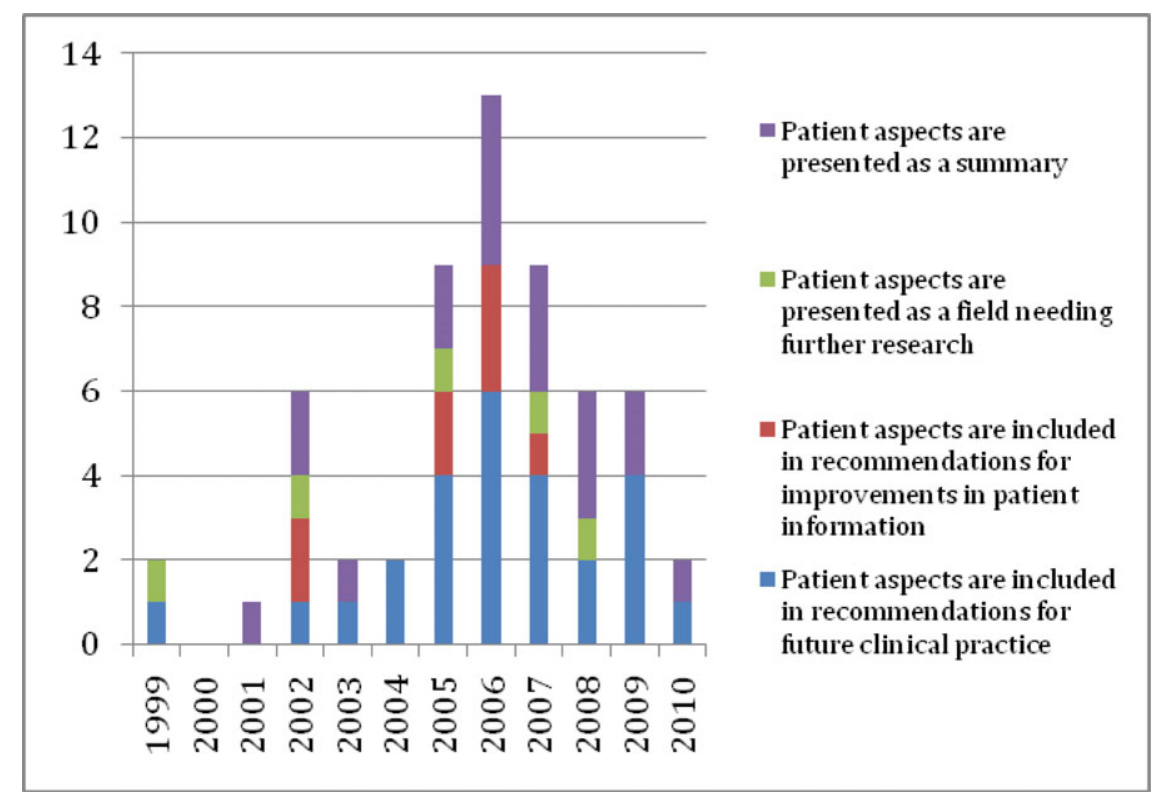

Figure 2. Patient aspects included in the concluding part of the reports.

data. The first assessment using qualitative methods was published in 2002 and the first using quantitative methods was published in 2001. While all fifty-eight reports included the patient assessment in the summary, more than half included patient aspects in the recommendations of the report, showing some significance of the patient assessment in the final con- clusions of the reports. The reports including patient aspects in the recommendations were significantly more frequently based on primary data, than the total group of reports assessed. This indicates that enhancing the assessments with primary research might be best practice for reaching conclusions relevant for decision making. From the review of 
the fifty-eight Danish HTA reports and from an article by Tjørnhøj-Thomsen and Hansen in this volume, a strong recommendation is that researchers base their decisions about methodology used in the assessments of patient aspects on clear and explicit reasoning (11).

The new HTA handbook, published in 2007 (3), developed chapters about patient aspects and qualitative methods from the former HTA handbook (2), emphasizing theoretical considerations in relation to production of knowledge. Whereas some time trends were identified in the present review, it is as yet too early to assess how the new handbook might have influenced the methodology for assessment of patient aspects. Fourteen HTA reports were published after 2007, and because the research presented in the reports might have been ongoing for several years, it can be discussed if the status of patient aspects in HTA reports should be drawn from the year the research was initiated, rather than from the year it was published. Just the two reports published in $2010(57 ; 58)$ may have been influenced by the handbook published in 2007. They both included a systematic literature search specific for the assessed patient aspects and an evaluation of the literature (relevance and internal validity) and included findings in the recommendations for the technology. It should be noted that this was the case in some of the previously published reports as well.

The distinct inclusion of patient aspects in Danish HTA's could be the result of the tradition of including four elements, one of these being patient aspects. Presenting patient aspects in a separate chapter in the HTA allows a more direct and explicit focus on the patient's problems, needs, experiences and preferences etc. in relation to a given technology. On the other hand, an integration of the aspects to be assessed, including that of the patient, and as found in two Danish HTA reports framed by a theoretical approach, might lead to a more holistic approach to HTA, opening up for an investigation into how patients and technology affect, and is affected by, each other.

The generating of HTA questions, and the theories and methodologies used to answer them, are informed by theoretical and methodological movements in the field of health policy research and HTA, as well as a result of the composition of the project group with respect to academic background and schooling. It is, however, crucial that the necessary choices in relation to aspects and methodology are transparent, if production and reporting of HTA is to adhere to scientific standards. Although the role of members of the project group was not investigated in the present review, the authors' experience is this, that researchers with competences within social aspects increasingly are involved in the production of Danish HTA's.

If health policy and decision making is to be patientfocused, it is important that HTAs in the future integrate patient aspects in recommendations of HTA. Although both inclusion and management of patient aspects are distinct and improving in the Danish HTA reports, there is room for im- provement in relation to methodology and inclusion of theory, as well as in the scientific managing, reporting, and production of clear recommendations.

\section{SUPPLEMENTARY MATERIAL}

Supplementary Table 1

www.journals.cambridge.org/thc2011024

\section{CONTACT INFORMATION}

Helle Ploug Hansen, PhD, mag.scient. (extended MA), (hphansen@health.sdu.dk), Professor in Humanistic Rehabilitation Research, Institute of Public Health Research Unit; Health, Man and Society \& National Research Centre for Cancer Rehabilitation, Anne Lee, MSc (Health), RN (ale@cast.sdu.dk), Senior Consultant, Centre for Applied Health Services Research and Technology Assessment, Christian Balslev van Randwijk, MA, PhD-student (crandwijk@health.sdu.dk), Institute of Public Health, Research Unit: Health, Man and Society, University of Southern Denmark, J.B. Winsløws Vej 9, DK-5000 Odense C, Denmark

\section{CONFLICT OF INTEREST}

All authors report they have no potential conflicts of interest.

\section{REFERENCES}

1. Facey K, Boivin A, Gracia J, et al. Patients' perspectives in health technology assessment: A route to robust evidence and fair liberation Int J Technol Assess Health Care. 2010;26:334340.

2. Kristensen FB, Hørder M, Poulsen PB, (eds.). Metodehåndbog for medicinsk teknologivurdering. (Health Technology Assessment Handbook). In Danish. Copenhagen: Statens Institut for Medicinsk Teknologivurdering; 2001.

3. Kristensen FB, Sigmund H, eds. Health technology assessment handbook. Copenhagen: Danish Centre for Health Technology Assessment, National Board of Health; 2007.

4. Lee A, Skött LS, Hansen HP. Organizational and patient-related assessments in HTAs: State of the art. Int J Technol Assess Health Care. 2009;25:530-536.

5. National Board of Health, Danish Centre for Health Technology Assessment. A review of organisational and patientrelated assessments in HTAs published by INAHTA members. Copenhagen: National Board of Health. Danish Centre for Health Technology Assessment; 2007.

6. National Board of Health. Perkutan vertebroplastik. Smertebehandling af osteoporotiske knoglebrud i ryghvirvler. Percutaneous vertebroplasty. Treatment of pain in osteoporotic fractures of vertebrae). In Danish. Copenhagen: National Board of Health. Danish Centre for Evaluation and Health Technology Assessment; 2004:6.

7. National Board of Health. Epo til behandling af blodmangel hos kraftpatienter - en medicinsk teknologivurdering. (EPO to treatment of Anaemia within cancer patients - a health technology assessment). In Danish. Copenhagen: National Board of 
Health. Danish Centre for Evaluation and Health Technology Assessment; 2004;6.

8. Olsen KR, Bjerregaard NC, Ibfelt EH, Laurberg S. Sundhedsøkonomisk analyse af diagnostiske strategier ved symptomer på ende- og tyktarmskraeft - en medicinsk teknologivurdering. (Health Economic Analysis of Diagnostic Strategies of Colorectal Cancer - a health technology assessment). In Danish. Copenhagen: National Board of Health. Monitoring \& Health Technology Assessment; 2009;11.

9. Randwijk CBV, Hansen HP. Inddragelse af patient aspekter $i$ danske MTV-rapporter - en statusopg $\phi$ relse. Arbejdspapir. (Patient Aspects in Danish HTA-reports - a status). In Danish. Copenhagen: National Board of Health; 2011.
10. Rasmussen SR, Kilsmark J, Hvenegaard A, Thomsen $\mathrm{JL}$, Engberg M, Lauritzen T, Søgaard J. Forebyggende helbredsundersøgelser og helbredssamtaler I almen praksis En sundhedsøkonomisk analyse af "Sundhedsprojekt Ebeltoft". (Preventing health screenings and health consultations in primary care - a health economic analysis of "Ebeltoft Health Promotion Project”). In Danish. Copenhagen: National Board of Health. Danish Centre for Evaluation and Health Technology Assessment; 2006;6.

11. Tjørnhøj-Thomsen T, Hansen HP. Knowledge in health technology assessment: Who, what, how? Int J Technol Assess Health Care. 2011;27:324329. 